\section{TREATMENT OF ASTHMa.}

"J. G. G." asks for suggestions for the treatment of a lady ace 60 , who has suffered from asthma for five years. Her fresent attack has lasted over six mouths. There is no history if heredity or neurosis, and there is no naso-pharyngeal abnormility. Potassium iodıde over prolonged periods, adrenaline, minge, lobelia, stramonium, and the exclusion of cats, teathers, etc., have all proved failures.

\section{Liquid Paraffin and Cancer.}

Dr. S. WaTSON SMFTH (Bournemouth) writes: In your issue of November Ist, p. 840, "13. K." asks whether those who see many cisses of malignant disease of the alimentary tract suspect the taking of liquid paraffin as a cause. Shortly after liquid paraffin cirne into more general use, the late Dr. Allan Jamieson of E tinbursh, in a letter to the BRITISH MEDICAL JounNaL, issued a warning and a reminder of the fact that paraffin workers were, o:t account of their employment, particularly liable to cancer. An enormous amount of parafin, solid as vell as liquid, must be c issumed daily in this country, and chiefly by those who are pist the ase of full development. One cannot easily avoid orlering it when so many preparations and so-called "foods" lave paraffin entering into their composition. Even with a guarantee it is impossible to be absolutely certain of purity or guarantee it is impossible to be absolutely certain of purity or pastes seems to harm few skins; if it cannot be tolerated, another vehicle is substituted. It has, however, to be remembered that ointments contaluing paraffins have only an accasional use for any particular patient and for seldom longer than i'a!s or weeks at a time. Taken internally for months or years, as it commonly is novadays, may make all the difference in risk, and the fer who have the misertune niference in rarafin well may ran a gresier risk of future malignant trouble. Fithin the past few years I have seen three caies of a dry form of dermatitis of both hands in motor-car mechsnics, apparently cansed by handling petrol and lubricants. It is understood that paraffin causes cancer because of impurities in it. If little or no absorption takes place in the irtestine, the paraflin being supposed to be inert. such impurities, if they exist, may yet quite easily exert their action anywhere in the body by becoming rssimilated. The risk attending the taking of paraffin in any form has for some years prevented my preseribing it except in special cases. If the Imperial ( ancer Research Fund could give some guidance or advice in the matter of the internal use of paraffin, I for one should be grateful.

\section{INCOME TAX.}

Partnership Assessment.

"DFLTA" inguires whether the inspector of taxes is justified in refusing to issne separate notices of assessment to two partuers.

* * The answer is "Yes." In 1907 the system of making separate assessments on partners was abolished by statute, and since then the assessment is required to be made in one sum on the frrm. At the same time it is the practice-so far as we know, w thont excention-for the inspector of tsxes to give any reasonable assi stance be can to the members of the firm in the task of div'ding the firm's liability correctly between the partners. If the inspector absolutely refuses to amplify the brief partnership statement he has given, "Delta "might send the statement to us with such further information on the point as he may be able to give.

Change in Appointment.

"H. A. H." was appointed to a lectureship at $£ 7 \equiv 0$ per annum a3 fiom December 12th, 19/1, and has been assessed to pay $£ 61$ 10s. jic $\mathrm{me}$ tax for the period to April 5 th, 1922. Is this correct? If $£ 800$ per annum "for the year 1921, up to November of that year."

* The sum of $£ 61$ 103. is correct, provided that "H. A. H." his had all his personal allowances from the assessment on his mevious earnings; we gather from the inspector's letter that this is the case. The only possibility of any adjustment being due to "H. A. H." is that the previous assessment should be for the period April 5th (and not January 1st), 1921, to the date in November as from which his former appointment terminated. "H. A.H." might find it advisable to obtain particulars from the inspector who dealt with that liability setting out exactly how the duty he paid for 1921-22 in that district was calculated.

\section{LETTERS, NOTES, ETC.}

Obstinate Nasil Catarrh in an INfant.

Dr. Lucy NaIsh, lecturer in osteology, University of Sheffield in reply to "G. E." (October 18th, p. 740), writes that the nasal catarrli is probably liept up by the frequent insertion of cottonwool soaked in various things into the nose, with a mistaken idea of cleansing it. All such applications should bs stopped and sncezing induced. 'The child will clear the nose by its own efforts, and iresh supplies of the bactericidal mucns will be able to act when the debris of old mucus is removed by the sneezing. 'To induce sueezing manipulation should be tried first: gentie massage of the forehead, particularly over the distribution area massage of the forehead, particularly over the distribution area Another way is tickling the orifice with dry cotton-wool, taking Another way is tickling the orifice with dry cotton-wool, taking sneezing can be induced by gently touching the septum of the nose with a probe covered with a few grains of powdered Castile soap; other substances with the same effect are Hudson's soap, gingar, or pepper. Only a few grains are required for a baby. When the sneeze has occurred the nose should be stroked gently downwards, as if "milking" it.

Rapin Stermization of Hypodermic Syringe and NeEdle.

Dr. W. JoHnson SMyTh (Bournemouth West), who has recently had ocession to note several instances of bad arms, sends the following simple method of sterilizing bypodermic syringes and needles: Place them in an ordinary test tube one-third full of water and heat to boiling point: a disc of cork as big as a of needle irom injury.

Cancer in African Natives.

Writing with regard to Dr. Old's letter published on October 11th (p. 689), Dr. Charles $F^{2}$. Harford (London) refers to the suggestion that suggestion sud anto-suggestion bay anto-suggest in their treatment. Dr. Harford thinks the clue should be followed up and that the leaders in cancer research should widen the scope of their inquiries and make use of the light which may come throngh modern psychoogy. He adds: The psycholofical factor in malignant disease has been considered by many, and in June, 1923, I had some correspondence on this subject with Dr. Archibald Leitch. In a letter which he was good enough to write to me on June 3ud of that year he gave various reasons for doubting the importance of mental stress in connexion with cancer, and in the course of his argument he wrote as follows: "But obove all, certain animal species, which do not impress us as having mental processes subject to the influence of emotions, contract malignant disease as commonly as, and in some cases more commonly than, human beings. The tame mouse; as you from the vicissitudes of life that the wild mouse has to face, develops cancer even more frequently than does the human being. Dogs, eats, horses, and even placid cows develop cancer. have given much thought to this interesting reply, and I have been led to connect this statement about cancer in animals with the knowledge we have about primitive races. The auima!s referred to are domestic animals, and in particular the tame mouse is "removed from the vicissitudes of life that the wild mouse has to face." This means that the life of liberty with its sporting chances has been exchanged for the enforced continement of the laboratory. Is there not a close analogy between these and the primitive races, who have too quickly exchanged the hybits of generations lor the artificial life of a civilization strictly European in pattern? In each case there has been a violent dislocation of instinctive forces with greater liability to interference even with physical processes.

\section{Dental Skiagrams.}

Sir JoHn O'Conor (Buenos Aires) writes: As complement to my note published in the BRITIsH MEDICAL JOURNAL, August 16th (p. 299), I should be obliged if you would allow me to state that I have every hope that within a short periol, as confirmatory diagnostic routine, we shall see in erery well appointed clinic
radiological general examination of the teeth linked with crtological, etc., examination of the blood.

\section{A Surgical Sling.}

Dr. J. M. Dewar (Edinburgh) informs us that a patient of his, a partially disabled ex-soldier, bas recently patented an adjustment for carrying surgical slings which eliminates strain on the wearer's neck. It is in the form of a waistbelt fitted with adjustable brace straps (each bearing a flat hook), which fit into slides on an ordinary sling. The weight is thus hung from the shoulders and equally distributed. When adjusted it remains firm and there is no discomfort, such as is caused by a slippiug knot. The adjustment has been worn frr seven months with comfort to the wearer, who formerly suffered pain and inconvenience from pressure on the neck.

\section{A Death Certification Problem.}

Dr. H. L. Prarsun (Newcastle) writes: I recently attended a young primipara in a premature labour-about the eighth for only fifteen minutes. The features were Mongolian in trpe, the right forearm was deformed, and there was ouly one lower limb, arising from the centre of the pelvis. The child resembled a "Punch and Judy" doll mounted on a stick. The most interesting feature was the entire absence of anus or external genitalia. As the child had had a distinct separate existence, a certiflcate of death had to be supplied, raising the difficult question-how to fll up the form.

\section{CORRECTION.}

Is the report of the scientific meeting of the Oxford Division pub. lished last week at page 815, for "fourteen" (col. 2, fourth line from top) read "four."

\section{VACANCIES.}

NOTIFICATroNs of offlces racant in universities, medical colleres, and of vacant resident and other appointments at hospitals, will be found at pages $40,41,44$, and 45 of our advertisement columns, and advertisements as to partnerships, assistantships, and locumtenencies at pages 42 and 43 .

A short summary of racant posts notifled in the advertisement columns appears in the Supplement at page 179. 